\title{
El reformismo fiscal borbónico en la Nueva Granada, balance y perspectivas*
}

José Joaquín Pinto Bernal

Profesor de la Universidad del Tolima (Colombia). Correo electrónico: josejoaqo@yahoo.com. El autor es magíster y doctor en Historia de la Universidad Nacional de Colombia (Colombia). Entre sus publicaciones recientes tenemos: "Fiscalidad e independencia en Quito, 1780-1830" en Investigaciones de Historia Económica Vol. 12 fasc.1 (2016) y "Fiscalidad e independencia en Santafé y Bogotá, 1780-1830" en América Latina en la Historia Económica Vol. 22, fasc. 3 (2015). Entre sus temas de interés están historia económica e historia fiscal.

Recibido: 16 de enero de 2016

Aprobado: 8 de marzo de 2016

Modificado: 12 de mayo de 2016

Artículo de investigación científica

DOI: http://dx.doi.org/10.15648/hc.29.2016.4

* $\quad$ Este artículo forma parte del proyecto: “Guerra y Hacienda: crisis y transformación de la Real Hacienda de Nueva España en la guerra de Independencia (1810-1821). Proyecto de Ciencia Básica CONACYT núm. 153670" financiado por el Consejo Nacional de Ciencia y Tecnología CONACYT (México).

Esta publicación está bajo una licencia Creative Commons Reconocimiento-NoComercial 4.0. 


\title{
El reformismo fiscal borbónico en la Nueva Granada, balance y perspectivas
}

\section{Resumen}

El artículo analiza las características de la categoría "reformas borbónicas" en la historiografía colombiana. La investigación abarca los aportes de la historiografía del siglo XIX, el uso de la categoría para campos específicos de estudio durante el siglo XX, y enfatiza en su empleo al interior de la historia económica y fiscal. Por último, se plantea la necesidad de ampliar la categoría para su empleo en el desarrollo de futuras investigaciones en la historia fiscal colonial.

Palabras clave: Reformas borbónicas, historiografía, Nueva Granada, historia fiscal.

\section{Bourbon fiscal reformism in Nueva Granada, balance and perspectives}

\begin{abstract}
The paper analyses the characteristics of the category "Bourbon reforms" in the Colombian historiography. The research includes the contributions of the historiography of the 19th century, the use of the category for specific fields of study during the 20th century, and emphasizes in its application within the economic and fiscal history. Finally, it states the need to expand the category for use in the development of future researches in the colonial fiscal history.
\end{abstract}

Key words: Bourbon reforms, historiography, Nueva Granada, fiscal history.

\section{O reformismo fiscal borbónico na Nova Granada, balanço e perspectivas}

\section{Resumo}

O artigo analisa as características da categoria "reformas borbónicas" na historiografía colombiana. A investigação abarca contribua-os da historiografía do século XIX, o uso da categoría para campos específicos de estudo durante o século XX, e enfatiza em seu emprego ao interior da história econômica e fiscal. Por último, propõe-se a necessidade de ampliar a categoria para seu emprego no desenvolvimento de futuras investigações na história fiscal colonial.

Palavras-chave: Reformas borbónicas, historiografía, Nova Granada, história fiscal. 


\section{Le réformisme fiscal bourbonien dans la Nueva Granada, bilan et perspectives}

\section{Résumé}

L'article analyse les caractéristiques de la catégorie «Réformes bourbonienne» dans l'historiographie colombienne. La recherche comprend les contributions de l'historiographie du XIXème siècle, l'utilisation de cette catégorie dans des domaines spécifiques d'étude pendant le XXème siècle, et finalement, elle met en relief son emploi à l'intérieur de l'histoire économique et fiscale. En définitive, le besoin d'étendre cette catégorie est envisagé afin de l'utiliser pour le développement des futures recherches dans le domaine de l'histoire fiscale coloniale.

Mots clés: Réformes bourboniennes, historiographie, Nueva Granada, histoire fiscale.

\section{INTRODUCCIÓN}

El devenir del siglo XVIII ha sido ampliamente estudiado en la historiografía colombiana a pesar del descuido del que fue objeto durante el siglo XIX, ello como producto de las narrativas que intentaban legitimar el proceso independentista o el ciclo de reformas liberales de mediados de siglo. Los primeros trabajos de la historiografía nacional trataron de manera tangencial aspectos generales que mostraban la ineficiencia e injusticia del mantenimiento del colonialismo, exceptuando el escrito de Groot ${ }^{1}$ quien desarrolló un recuento pormenorizado de distintos procesos de la vida social durante el periodo. Solo hasta mediados del siglo XX revivió el interés por la exploración de diversos aspectos del XVIII, en especial sobre las políticas emprendidas por la dinastía borbónica.

La historiografía ha acuñado la categoría "reformas borbónicas" para englobar la serie de acontecimientos desarrollados durante el siglo XVIII como producto de las políticas metropolitanas en la Nueva Granada; en tal sentido ha configurado unos contenidos específicos a la misma, destacándose:

a. Una periodización donde se prioriza el papel del Virrey Flórez y la

1 José Manuel Groot, Historia eclesiástica y civil de Nueva Granada (Bogotá: Medardo Rivas, 1869). 
visita de Francisco Gutiérrez como punto de inicio de las reformas, culminando en 1810 con el inicio del proceso de independencia.

b. Unos acontecimientos centrales que cumplen el papel de detonantes para su desarrollo, predominando la finalización de la Guerra de los Siete Años y la iniciativa de los ministros de Carlos III tras la pérdida de La Habana y Filipinas.

c. Una doctrina orientadora del proceso centrada en el mercantilismo español y el despotismo ilustrado.

d. Un esquema de interacción entre los sectores involucrados, donde el gobierno metropolitano cumple un papel activo a la hora de diseñar e implementar reformas, mientras que los actores locales cumplen un papel reactivo a través de revueltas o pasivo.

El presente trabajo realiza una revisión historiográfica donde se evidencia cómo desde distintos trabajos se ha contribuido a la conformación de las antedichas características, demostrando cómo a la luz de recientes investigaciones tanto la periodización, los elementos desencadenantes de las reformas, la doctrina orientadora y el esquema de interacción entre los sectores involucrados pueden ser ampliados para el desarrollo de investigaciones en el campo de la historia fiscal. Para tal fin, se ha hecho una exhaustiva lectura de los textos de historia que se han ocupado del periodo, haciendo omisión de los elaborados por observadores directos como los tratadistas españoles del siglo XVIII, los ilustrados neogranadinos o los funcionarios de la corona, debido a que nuestro fin no es el de puntualizar los contenidos propios de la política imperial ni su impacto real, sino la caracterización de la categoría con base en la historiografía y la reflexión en torno a la ampliación de sus marcos de referencia.

El texto está dividido en cuatro secciones. En la primera se da cuenta de los componentes que la historiografía del siglo XIX aportó para la posterior formación de la categoría. La segunda sección está dedicada a la exposición de los elementos aportados por la historia institucional, administrativa, territorial y militar. La tercera sección aborda las lecturas realizadas desde la historia económica y fiscal. Las conclusiones se dedican a la configuración de una propuesta que emplee la categoría "reformas borbónicas" desde un enfoque más amplio para el abordaje de la fiscalidad. 


\section{LA HISTORIOGRAFÍA DECIMONÓNICA EN LA CONFIGURACIÓN DE LA CA- TEGORÍA}

En los primeros ejercicios de escritura histórica a comienzos del siglo XIX se empezaron a prefigurar las aristas básicas que compondrían la categoría "reformas borbónicas". Los historiadores decimonónicos definieron un contexto territorial, una periodización que establecía motores para el inicio de las reformas, además de perfilar unos protagonistas y un modo de interacción entre ellos en el diseño, implementación y recepción de las políticas del Gobierno de Indias en la Nueva Granada.

Un primer grupo de trabajos estuvo direccionado por los aportes de José Manuel Restrepo ${ }^{2}$ quien desarrolló los pormenores del proceso independentista entre 1700 y 1832; la elección del periodo es de suma importancia ya que para el autor los cambios acontecidos en el siglo XVIII son claves para comprender el movimiento emancipatorio que iniciaría en 1810 con la formación de las Juntas Autónomas de Gobierno y culminaría con la separación de la República de Colombia en 1832. Para Restrepo, el ascenso al trono de la dinastía borbona sería la pieza clave para el inicio de la toma de medidas para el mejoramiento de la administración y el gobierno colonial, en respuesta a los clamores internos ante los desórdenes propiciados por los Presidentes de la Audiencia y a los informes de sus fieles servidores ${ }^{3}$.

Este autor es claro en afirmar que los cambios en la política borbónica, además de obedecer al simple relevo de dinastía, se debieron al desarrollo de la guerra de sucesión que puso en el trono a los nuevos gobernantes, de la Oreja de Jenkins que aceleró el proceso definitivo de formación del Virreinato pospuesto desde 1719, y a la de los siete años que obligó a la corona a intensificar su política. Especial énfasis otorgó Restrepo a las trasformaciones emprendidas tras la visita de Gutiérrez de Piñeres en 1778, tales como: la culminación de la puesta bajo administración directa de los estancos de tabaco y aguardiente, la elaboración del plan para el manejo de

2 José Manuel Restrepo, Historia de la Revolución de la República de Colombia (París: Librería Americana, 1827).

3 José Manuel Restrepo, Historia de la... 
alcabalas y la instauración de las direcciones generales de cada ramo con sede en Santafé, medidas que propiciaron la rebelión de los comuneros y el surgimiento del deseo independentista. Esta postura fue recogida por Samper ${ }^{4}$ y por Galindo ${ }^{5}$ quienes como parte de los radicales liberales de mediados del siglo XIX, elaboraron sus relatos denunciando las injusticias de la política económica y fiscal colonial, rastros que debían ser eliminados por las nuevas administraciones para la promoción del desarrollo económico, haciendo énfasis de nuevo en las determinaciones instauradas por la corona desde 1778 .

Desde otra perspectiva, José María Groot ${ }^{6}$ escribió su relato con arreglo a una temporalidad lineal haciendo énfasis en las condiciones internas que prefiguraron las características del gobierno civil y eclesiástico en la Nueva Granada. Allí, el autor recurre a exponer cada una de las medidas implementadas por los Virreyes y las autoridades locales, así como sus repercusiones en la sociedad. El trabajo de Groot $^{7}$ no hace explícita mención a un motor para el inicio de las reformas que obedecen a las necesidades propias de la Corona al interior del Virreinato, por tanto las trasformaciones son producto del ascenso al trono de la nueva dinastía, proceso que abarcó desde 1700 hasta 1810, sin dar especial énfasis a algún periodo específico pero ahondando en detalles durante todo el siglo.

Se hacen claras así dos perspectivas que aportan elementos para el desarrollo de la categoría "reformas borbónicas". De una parte, la primera expresa un ámbito territorial de análisis que involucra el conjunto del imperio, mientras la segunda hace énfasis en la exposición densa del contexto interno. La perspectiva amplia permite ubicar a las guerras entre potencias como motores para los cambios de la política colonial, mientras la otra sugiere que las disputas internas que afectan los intereses metropolitanos sirven de estímulo a la voluntad individual de los virreyes y oidores para efectuar cambios.

4 José María Samper, Ensayo sobre las revoluciones políticas y la condición social de las repúblicas colombianas (París: Imprenta de E. Thunot y Cía., 1861).

585 Aníbal Galindo, "Apuntamientos para la historia económica y fiscal del país", en Estudios económicos y fiscales, ed. Aníbal Galindo (Bogotá: Imprenta de H. Andrade, 1880), 169-256.

6 José Manuel Groot, Historia eclesiástica...

7 José Manuel Groot, Historia eclesiástica... 
En lo que atañe a la periodización, la primera vertiente basándose en un marco de referencia espacial ampliado y el papel de las guerras para los cambios en la política, ofrece una periodización básica:

- 1717-1739: fallida formación del Virreinato.

- 1739-1778: ante la Guerra de la Oreja de Jenkins se instaura el Virreinato.

- 1778-1810: como producto de las necesidades surgidas de la Guerra de los Siete Años las trasformaciones se acentúan provocando el levantamiento popular y el advenimiento del sentimiento independentista.

La segunda perspectiva no ofrece tales características pues se fija más en los periodos de los virreyes de turno, por tanto los lapsos que se utilizan para el estudio de los acontecimientos políticos y económicos, coinciden con los espacios de tiempo en los cuales gobernó cada Presidente de la Audiencia o Virrey.

Por último, los trabajos plantean dos esquemas de causación para la interpretación de las actuaciones de los grupos involucrados. Por una parte, el papel activo es tomado por la corona que con base en la determinación de unos objetivos plantea una política específica a la cual responden los sectores sociales. La otra perspectiva determina que las medidas no son producto de causas externas sino de la visión que los gobernantes internos tienen de la situación local, ante lo cual responden propiciando el orden.

Esta contextualización, establecimiento de causantes para el desarrollo de las reformas, periodización y esquema de interacción de grupos involucrados, sirvió como base para la elaboración de los trabajos desarrollados en el siglo XX, momento para el cual (desde distintas perspectivas y analizando tópicos específicos) autores de distinta procedencia disciplinar retomaron y ampliaron los marcos de referencia de la categoría, lo cual será estudiado a continuación.

\section{VISIONES ESPECÍFICAS DE LAS REFORMAS}

Durante el siglo XX la historiografía realizó exploraciones en distintas esferas sociales del siglo neogranadino de las luces; algunos fijaron sus inda- 
gaciones en el plano institucional, otros se concentraron alrededor de los pormenores de la organización territorial y la distribución de la población, desde otra área se estudió la cuestión militar, y por último, las implicaciones sociales de los cambios en la política de gobierno para la generación de movimientos de protesta.

Desde el punto de vista institucional la preocupación por la compresión del desarrollo de las atribuciones de las diversas autoridades coloniales durante el siglo XVIII, fue tema central del trabajo de Ots Capdequi ${ }^{8}$, para quien la marca distintiva del periodo fue la imposición del despotismo ilustrado como sistema político importado desde Francia, cuyo rasgo característico estaba en la concentración del poder en las Secretarías de Estado y en la figura del Rey minimizando el margen de acción de poderes locales, fenómeno que generó en última instancia su fracaso al carecer de arraigo popular ${ }^{9}$. Posterior a ello, apareció el trabajo de Garrido ${ }^{10}$ quien relató los pormenores de la primera creación del Virreinato de la Nueva Granada y su efímera existencia, estudiando las características administrativas de su configuración y las causas del fracaso de su instauración desde el ámbito local y no dentro del conjunto del imperio. Un ejercicio similar fue realizado por Sergio Elías Ortiz ${ }^{11}$, quien no solo abarca el primer intento de formación del Virreinato sino todo el siglo XVIII, lo que le permitió hacer un balance general de la gestión y los resultados de los gobiernos de cada uno de los virreyes.

Recientemente el enfoque que evalúa el desarrollo institucional se ha concentrado no solo en el estudio de las medidas aplicadas por los virreyes, además de ello se ha indagado sobre los choques entre autoridades locales por las nuevas disposiciones y los obstáculos para la aplicación de las políticas. Ruiz Rivera ${ }^{12}$ mostró las tensiones entre el visitador Gutiérrez de

8 José María Ots Capdequi, Instituciones de Gobierno del Nuevo Reino de Granada durante el siglo XVIII (Bogotá: Universidad Nacional de Colombia, 1951).

9 José María Ots Capdequi, Instituciones de..., 16.

10 María Teresa Garrido Conde, La primera creación del virreinato de Nueva Granada, 1717-1723 (Sevilla: Escuela de Estudios Hispanoamericanos, 1965).

11 Sergio Elías Ortiz, Gobernantes de capa y espada, Tomos I y II (Bogotá: Ediciones Lerner, 1970).

12 Julián Ruiz Rivera, "El reformismo local en el Virreinato de la Nueva Granada", Temas Americanistas No. 13 (1997). 
Piñeres y el protector de indios Moreno y Escandón; Restrepo ${ }^{13}$ ha fijado su atención en el gobierno del Virrey Solís analizando el devenir de las medidas implementadas por este para el mejoramiento de la administración y el recaudo fiscal. En este enfoque es necesario mencionar los esfuerzos por la compilación y edición de fuentes primarias que dan cuenta de la gestión de cada Virrey, destacándose los trabajos de Posada e Ibáñez ${ }^{14}$, Colmenares ${ }^{15}$ y Alameda ${ }^{16}$. Recientemente una visión integral del proceso de trasformación administrativo ha sido propuesta por Maqueda ${ }^{17}$, quien a diferencia de los anteriores trabajos de Ots Capdequi ${ }^{18}$ y Ortiz ${ }^{19}$, plantea que el ciclo reformista se concentró en el reinado de Carlos III y muestra a las guerras entre potencias como factor determinante.

La perspectiva institucional logró vincular los ámbitos territoriales local y amplio para su análisis, aunque mantiene el debate entre un ciclo reformista anterior al reinado de Carlos III, presentándose trabajos que mantienen el énfasis del estudio entre 1760 y 1810. Como motores de desarrollo de la reforma se encuentran la guerra y la reconfiguración de la política metropolitana, misma que está prefigurada por el despotismo ilustrado, resaltando el papel de las reacciones internas a los cambios, como factores centrales que determinan la aplicación pero no el diseño de las medidas.

Otro de los enfoques desde los cuales se ha estudiado el impacto de las políticas implementadas durante el siglo XVIII en la Nueva Granada, se ha esforzado por evaluar los choques entre las autoridades centrales y locales en torno a los procesos de reordenamiento del territorio, a través de las conducciones de indios y de la delimitación de jurisdicciones administra-

13 Margarita Restrepo, Nueva Granada en tiempo del Virrey Solís, 1753-1761 (Bogotá: Universidad del Rosario, 2009).

14 Eduardo Posada y Pedro Ibáñez, Relaciones de mando. Memorias presentadas por los gobernantes del Nuevo Reino de Granada (Bogotá: Imprenta Nacional, 1910).

15 Germán Colmenares, Relaciones de mando e informes de los gobernantes de la Nueva Granada (Bogotá: Banco Popular, 1989).

16 Raúl Alameda, Virreyes y funcionarios neogranadinos ante las reformas borbónicas, 1729-1818 (Bogotá: Academia Colombiana de Ciencias Económicas, 2014).

17 Consuelo Maqueda, El Virreinato de la Nueva Granada, 1717-1780. Estudio institucional (Madrid: Dykinson/Ediciones Puertollano, 2007).

18 José María Ots Capdequi, Instituciones de Gobierno...

19 Sergio Elías Ortiz, Gobernantes de capa... 
tivas. Se destacan los trabajos de Herrera Ángel ${ }^{20}$ para el caso de la región aledaña a Santafé, quien posteriormente ampliaría el marco de indagación hacia la costa Atlántica y toda la región central de la actual Colombia ${ }^{21}$, y los de Conde Calderón ${ }^{22}$, quien estudia las tensiones surgidas en Cartagena como producto de las medidas aplicadas para la reorganización de la población creciente, en favor de un mejor control social.

Desde otra perspectiva, las investigaciones empezaron a girar ya no solo en torno al estudio de las medidas implementadas a nivel administrativo o territorial, sino en una de sus finalidades, el ámbito militar. Es así, cómo los trabajos de Marchena ${ }^{23}$ han aportado importante material para la comprensión de la organización, funcionamiento y obstáculos de mantenimiento del ejército americano, trabajo que ha sido ampliado por Kuethe ${ }^{24}$ concentrándose en el impacto social de la formación del ejército regular durante el último periodo de dominio colonial.

El caso de la Nueva Granada y la configuración del gasto para el sostenimiento del sistema de defensa imperial a través del análisis de las series fiscales, ha sido abordado por Jara ${ }^{25}$, por otra parte Serrano ${ }^{26}$ ha trabajado sistemáticamente las cuentas de cargo y data de Panamá, Santa Marta, Riohacha, Cartagena y Portobelo. Desde este enfoque la razón fundamental para el inicio de la reforma se encuentra en el deseo de la corona por conseguir recursos encaminados para enfrentar las guerras coloniales, con base en fondos internos, recaudados en cada una de sus posesiones; en tal sentido la periodización abarca todo el siglo XVIII.

20 Martha Herrera Ángel, Poder local, población y ordenamiento territorial en la Nueva Granada, siglo XVIII (Bogotá: Archivo General de la Nación, 1996).

21 Martha Herrera Ángel, Ordenar para Controlar: Ordenamiento Espacial y Control Político en las Llanuras del Caribe y en los Andes centrales neogranadinos, siglo XVIII (Bogotá: Universidad de los Andes, 2014).

22 Jorge Conde Calderón, "Reformas borbónicas y reordenamiento del espacio en el Nuevo Reino de Granada. El caso de la providencia de Cartagena siglo XVIII”, Revista Historia Caribe No. 1 (1995): 5-24.

23 Juan Marchena, Ejército y milicias en el mundo colonial americano (Madrid: Mapfre, 1992).

24 Allan Kuethe, Reforma militar y sociedad en la Nueva Granada: 1773-1808 (Bogotá: Banco de la República, 1993).

6225 Álvaro Jara, El imperio español en América. 1700-1820 (Santiago de Chile: Editorial Sudamericana, 2011).

26 José Manuel Serrano, Fortificaciones y tropas: el gasto militar en tierra firme, 1700-1788 (Sevilla: Escuela de Estudios Hispanoamericanos, 2004). 
Fuente de preocupación de la historiografía colombiana también ha sido el papel de las políticas en la formación de movimientos sociales de oposición como la revuelta de los comuneros en 1781. Uno de los primeros trabajos en esta vertiente fue el desarrollado por Liévano Aguirre ${ }^{27}$ quien retomando el concepto de despotismo ilustrado valoró de forma negativa las nuevas directrices implementadas por la corona para la mejor administración de las colonias, ya que estaban diseñadas para solo beneficiar a la metrópoli, generando el descontento social popular y de la élite criolla. Posterior a ello, Phelan ${ }^{28}$ categorizaría las reformas de Carlos III como una revolución política, en aras de quitar el poder a las élites locales con el fin de consolidar un programa de modernización defensiva en beneficio de la metrópoli. Siguiendo el énfasis del estudio de las políticas implementadas por Carlos III, Fisher, Kuethe y McFarlane ${ }^{29}$ publicarían un extenso compilatorio de trabajos monográficos comparando el papel de las reformas en el desarrollo de movimientos sociales de insurrección.

Recientemente, un nuevo enfoque se ha consolidado con el trabajo de Alzate Echeverry ${ }^{30}$ quien estudia el impacto de las reformas en el ámbito local, haciendo énfasis en los cambios de las condiciones de salubridad en la población de la capital del Virreinato.

Como se evidencia, los trabajos desarrollados desde la historia institucional, del territorio, militar y social, han acogido una visión amplia para el análisis de las reformas, entendiéndolas como fenómenos pertenecientes al amplio espectro colonial, no solo sujetas a la voluntad de los gobernantes locales de turno. En tal sentido, la reestructuración de algunos aspectos del Gobierno de Indias obedeció a las necesidades que la corona experimentó como producto de las guerras con otras potencias, proceso que se desarrolló a lo largo de todo el siglo XVIII, lo que provocó movimientos

27 Indalecio Liévano Aguirre, Los grandes conflictos sociales y económicos de nuestra historia (Bogotá: Ediciones Tercer Mundo, 1964).

28 John Leddy Phelan, El pueblo y el Rey (Bogotá: Carlos Valencia Ediciones, 1978).

29 John Fisher, Allan Kuethe y Anhotny McFarlane, Reform and Insurrection in Bourbon New Granada and Peru (Louisiana: Louisiana State University Press, 1990).

30 Adriana Alzate, Suciedad y orden: Reformas sanitarias borbónicas en la Nueva Granada 1760-1810 (Bogotá: Universidad del Rosario, 2007). 
sociales de protesta ante la mayor presión fiscal que implicó el aumento del recaudo. Sin embargo, es preciso reseñar que persiste en estos enfoques una mayor atención a los acontecimientos desarrollados durante el reinado de Carlos III.

\section{LA REFORMAS EN LA HISTORIA ECONÓMICA Y FISCAL}

Indudablemente uno de los campos más fructíferos ha sido el de la historia económica en donde el estudio del desarrollo de las actividades comerciales, la agricultura, la minería, el desempeño global, el pensamiento y la política económica ha generado importantes avances para la construcción de un concepto de reformas borbónicas, a través del uso riguroso de las cuentas fiscales para algunos de sus principales estimativos. Sin embargo, son contadas las excepciones de trabajos que no se centran únicamente en el estudio de los acontecimientos durante la segunda mitad del siglo, dejando de lado las transformaciones acaecidas anteriormente.

Las actividades comerciales y los obstáculos para su desarrollo, como producto de la política intermitente de permitir el tráfico con colonias extranjeras y neutrales durante las guerras en la década de los 80 , fueron objeto de estudio de MacFarlane ${ }^{31}$ quien construyó series completas para el análisis de la composición del comercio externo. Trabajos posteriores retomaron la senda trazada por las investigaciones de MacFarlane concentrando su preocupación en la segunda mitad del siglo, siendo el intento más completo el elaborado por Pogonyi ${ }^{32}$. En su disertación, Pogonyi comprende las reformas como un esfuerzo administrativo tendiente a mantener el monopolio comercial para incrementar el ingreso fiscal a través de una recomposición administrativa, en el marco de lo que llamaría el primer ciclo de las Reformas Carolinas comprendidas entre 1759 y 1778. Este trabajo es uno de los más ricos en fuentes de tipo cualitativo así como en las de orden cuantitativo, siendo el primero que abordó con sistematicidad los

31 Anthony McFarlane, "El comercio exterior del Virreinato de la Nueva Granada: Conflictos en la política económica de los Borbones, 1783-1789", Anuario Colombiano de Historia Social y de la Cultura No. 6-7 (1972).

32 Micklos Pogonyi, "The search for trade and profits in Bourbon Colombia: 1765-1777" (tesis de Doctorado en Historia, The University of New Mexico, 1978). 
registros de la Real Hacienda en la Nueva Granada. Este cuadro ha sido completado recientemente por el trabajo de Bohórquez ${ }^{33}$ quien analizó el comportamiento del principal puerto hasta previo la independencia.

Pero no solo el comercio externo ha sido objeto de estudio, el reciente trabajo de Moreno ${ }^{34}$ ha logrado evidenciar la interacción del mercado interno con base en la comercialización de bienes extranjeros, gracias al cálculo de las magnitudes de las importaciones y los destinos de los bienes de Castilla. Por otra parte, las investigaciones de Muñoz y Torres ${ }^{35}$ han abierto un nuevo campo de indagación al estudiar el comercio interno contradiciendo el concepto de "archipiélagos económicos" formulado por Nieto Arteta $^{36}$ para referirse a las regiones de la Nueva Granada.

Otro de los sectores analizados ha sido el del desarrollo de la agricultura a través de las series de recaudo de diezmos, trabajos que han sugerido un aumento de la producción debido al incremento de la demanda interna, especialmente de las regiones mineras del sur y noroccidente, lo que impactó el centro de la actual Colombia como lo han demostrado Brungar$\mathrm{dt}^{37}$, Díaz ${ }^{38}$, para el Valle del Cauca y Melo para Popayán ${ }^{39}$. Como se mencionó, este buen rendimiento se debió en gran parte al incremento de la producción de metales, jalonada por las medidas adoptadas por la Corona, tendientes a la pacificación de pueblos de indios y su reorganización territorial, la reducción de los quintos, el aumento del precio para la compra de oros y la administración directa de las casas de la moneda, tal y como

33 Jesús Bohórquez, "Más para entretener la miseria que despertar la codicia: los frutos del comercio y los mercados imperiales durante el nacimiento del liberalismo. Nueva Granada, 1780-1810”, Anuario Colombiano de Historia Social y de la Cultura Vol. 36 No. 1 (2009).

34 Nathalie Moreno, "Circulación de efectos de Castilla en el Virreinato de la Nueva Granada a finales del siglo XVIII", Fronteras de la Historia Vol. 18 No. 1 (2013).

35 Edwin Muñoz y James Torres, "La función de Santafé en los sistemas de intercambio en la Nueva Granada a fines del siglo XVIII", Fronteras de la Historia Vol. 18 No. 1 (2013).

36 Luis Eduardo Nieto Arteta, Economía y cultura en la historia de Colombia (Bogotá: Ediciones Tercer Mundo, 1962).

37 Maurice Brungardt, "Tithe production and patterns of economic change in central Colombia, 17641833" (tesis de Doctorado en Historia, University of Texas, Austin, 1974).

38 Zamira Díaz, Guerra y economía en las haciendas. Popayán, 1780-1830 (Cali: Universidad del Valle, 1983).

39 Jorge Orlando Melo, La producción agrícola en Popayán en el siglo XVIII, según las cuentas de diezmos,http://jorgeorlandomelo.com/bajar/popayan.pdf (11/07/2015). 
ha sido abordado para la región de Antioquia por González $z^{40}$ y Twinam ${ }^{41}$, para el suroccidente por Colmenares ${ }^{42}$ y $\mathrm{Melo}^{43}$, y más recientemente desde un enfoque general por Torres ${ }^{44}$ quien analizó el papel del sector y su influencia en el desempeño económico global de todo el Virreinato, así como el impacto de las medidas de envilecimiento en el sector minero ${ }^{45}$.

Desde la historia económica también se han dado avances en otros aspectos no relacionados directamente con el desempeño de las actividades productivas. Tal es el caso de Rodríguez ${ }^{46}$ y Rodríguez y Arévalo ${ }^{47}$ quienes estudiaron los pormenores del pensamiento mercantilista y su aplicación en la Nueva Granada, enfoque que ya había sido empleado por González ${ }^{48}$ quien elaboró un completo balance de las medidas tomadas por los borbones para el mejoramiento de la administración y recaudo fiscal desde 1759. Otra preocupación ha sido la relacionada con la recepción de las políticas imperiales por parte de la élite criolla y su impacto en la formación de un pensamiento crítico frente a la política fiscal y comercial, como lo han abordado Bohórquez ${ }^{49}$ y Silva ${ }^{50}$.

En la actualidad uno de los campos de mayor debate se encuentra en la

40 Margarita Gonzáles, "El resguardo minero de Antioquia", Anuario Colombiano de Historia Social y de la Cultura No. 9 (1979).

41 Ann Twinam, Mineros, comerciantes y labradores: las raíces del espíritu empresarial en Antioquia, 1763-1810 (Medellín: Fondo Rotatorio de Publicaciones FAES, 1985).

42 Germán Colmenares, Historia económica y social de Colombia (Bogotá: Tercer Mundo, 1997).

43 Jorge Orlando Melo, Producción de oro y desarrollo económico en el siglo XVIII, http://www. jorgeorlandomelo.com/bajar/oroydesarrollo.pdf (11/07/2015).

44 James Torres, Minería y moneda en el Nuevo Reino de Granada. El desempeño económico en la segunda mitad del siglo XVIII (Bogotá: Instituto Colombiano de Antropología e Historia, 2013).

45 James Torres, "Monedas de antiguo y nuevo cuño. Envilecimiento y reacuñación en el Nuevo Reino de Granada en la segunda mitad del siglo XVIII", Memoria y Sociedad Vol. 18 No. 36 (2014).

46 Óscar Rodríguez Salazar, "El pensamiento económico en la formación del Estado granadino, 17801830", Historia Crítica No. 3 (1990).

47 Decsi Arévalo Hernández y Óscar Rodríguez Salazar, Gremios, reformas tributarias y administración de impuestos en Colombia (Bogotá: Universidad Externado, 2001).

48 Margarita Gonzáles, "La política económica virreinal en el Nuevo Reino de Granada: 1750-1810", Anuario Colombiano de Historia Social y de la Cultura No. 11 (1983).

49 Jesús Bohórquez, Luces para la economía. Libros y discursos de economía política en el Atlántico español durante la era de las revoluciones (Nueva Granada, 1780-1811) (Bogotá: Instituto Colombiano de Antropología e Historia, 2013).

50 Renán Silva, Cultura escrita, historiografía y sociedad en el Virreinato de la Nueva Granada (Bogotá: La Carreta Editores, 2015). 
determinación del impacto de las reformas en el crecimiento económico del Virreinato y sus regiones durante el siglo XVIII.

Uno de los esfuerzos más completos fue el de MacFarlane ${ }^{51}$, quien enfatizando en las reformas implementadas desde 1778, logró construir un cuadro de la economía, el gobierno, la política y la crisis del orden colonial. Los esfuerzos en este campo han permitido la elaboración de cálculos del PIB durante la segunda mitad del siglo XVIII, como en el caso del trabajo de Kalmanovitz ${ }^{52}$ quien otorgó un significativo peso al crecimiento poblacional para el impulso de las actividades productivas, donde a pesar de una fuerte carga fiscal, el crecimiento se mantuvo hasta la independencia. Por otra parte, Meisel $^{53}$ a través de la reconstrucción de las series de cargos de las Cajas Reales de la Nueva Granada efectuó un cálculo del PIB demostrando el buen desempeño del sector productivo entre 1761 y 1800 , sin embargo las cifras de las Cajas están agrupadas en macrorregiones con una periodización quinquenal, haciendo prácticamente imposible su uso para el estudio de conjuntos territoriales más reducidos o cambios coyunturales de corta duración. Frente al desempeño económico del Virreinato, recientemente el trabajo de Torres ${ }^{54}$ ha incluido nuevos cálculos sobre la producción minera, los precios y la tasa de interés, lo que le permitió establecer las fluctuaciones de las actividades económicas durante el siglo XVIII y no solo una serie de armónico crecimiento. Llama la atención que los cuatro trabajos excluyen de sus análisis el estudio de la Audiencia de Quito y Panamá como partes integrantes del Virreinato con fuertes vínculos comerciales, administrativos y políticos.

En este mismo enfoque se han venido desarrollando trabajos que permiten dar una mirada del desenvolvimiento económico durante el siglo XVIII pero de forma más detallada en términos regionales, como el traba-

51 Anthony McFarlane, Colombia antes de la independencia. Economía, sociedad y política bajo el dominio borbón (Bogotá: Banco de la República, 1997).

52 Salomón Kalmanovitz, "El PIB de la Nueva Granada en 1800: auge colonial, estancamiento republicano", Revista de Economía Institucional Vol. 8 No. 15 (2006).

53 Adolfo Meisel, "Crecimiento, mestizaje y presión fiscal en el virreinato de la Nueva Granada, 17601800”, Cuadernos de Historia Económica y Empresarial No. 28 (2011).

54 James Torres, Minería y moneda en el nuevo... 
jo de Patiño ${ }^{55}$ para el caso antioqueño, Soloudre-La France ${ }^{56}$ para la región del Alto Magdalena, Torres ${ }^{57}$ para Popayán a través de las series de precios y amonedación, Kalmanovitz y Lópe $z^{58}$ para el caso de Santafé, y Torres ${ }^{59}$ a través de las series de fluctuación de las tasas de interés del crédito comercial.

La historia económica del siglo XVIII ha alimentado y ha sido sustentada por la historia fiscal, trabajos que se han preocupado por el estudio de los cambios administrativos y de la política impositiva, el balance del rendimiento e impacto social de diversos ramos de recaudo, los alcances de la política del reformismo a nivel regional o estudios generalizados para el conjunto del Virreinato. En el campo de las variaciones de las leyes el trabajo más completo fue desarrollado a principios del siglo XX por Clímaco Calderón ${ }^{60}$ quien elaboró un pormenorizado balance de los cambios en cada ramo desde los Austrias hasta el preámbulo del periodo independentista, labor que fue complementada por Abel Cruz Santos ${ }^{61}$ quien correlacionó dichas transformaciones con los pormenores de las administraciones de cada uno de los virreyes, mientras que Rodríguez ${ }^{62}$ esclareció el marco administrativo y funcionamiento de las Cajas Reales de todo el territorio neogranadino; trabajo que fue acompañado por los esfuerzos de Mora $^{63}$ quien transcribió las cuentas de cargo y data de todas las cajas en 1783.

55 Beatríz Patiño, Riqueza, pobreza y diferenciación social en la Provincia de Antioquia durante el siglo XVIII (Medellín: Universidad de Antioquia, 2011).

56 Renée Soulodre-La France, Región e imperio: el Tolima Grande y las reformas borbónicas en el siglo XVIII (Bogotá: Instituto Colombiano de Antropología e Historia, 2004).

57 James Torres, "El comportamiento de los precios en una economía preindustrial: Popayán, virreinato de Nueva Granada, 1706-1819”, Cuadernos de Economía Vol. 34 No. 66 (2015).

58 Salomón Kalmanovitz y Edwin López, "La economía de Santafé de Bogotá en 1810", Revista de Historia Económica/Journal of Iberian and Latin American Economic History Vol. 30 No. 2 (2012).

59 James Torres, "Tasas de interés y desempeño económico: el crédito comercial en Santafé de Bogotá, 1760-1810”, América Latina en la Historia Económica Vol. 21 No. 3 (2014).

60 Clímaco Calderón, Elementos de hacienda pública (Bogotá: La Luz, 1911).

61 Abel Cruz Santos, Economía y Hacienda Pública (Bogotá: Lerner, 1965).

62 Óscar Rodríguez Salazar, "Anotaciones al funcionamiento de la Real Hacienda en el Nuevo Reino de Granada, siglo XVIII", Anuario Colombiano de Historia Social y de la Cultura No. 11 (1983).

63 Gilma Mora de Tovar, "Las cuentas de la Real Hacienda y la política fiscal en el Nuevo Reino de Granada: Materiales para su estudio a fines del siglo XVIII", Anuario Colombiano de Historia Social y de la Cultura No. 11 (1983). 
Desde el ámbito regional existe un predominio del estudio de la Caja Real de Cartagena, que ha sido abordada por Álvaro Jara ${ }^{64}$ quien analizó el situado proveniente de Quito, por Meisel ${ }^{65}$ cuyo trabajo determinó el papel del situado para la consolidación del sistema de defensa en la economía cartagenera, y por Rodríguez y Arévalo ${ }^{66}$ quienes estudiaron los ramos de ingreso y egreso de forma desagrupada. La Caja de Santafé también ha sido analizada por Pinto ${ }^{67}$ quien estudia el impacto cuantitativo de las reformas en la composición y dinámica del cargo y data desde 1780, y por Muñoz ${ }^{68}$ quien trabajó los cambios sufridos por la estructura de ingreso durante el periodo temprano republicano. Otras regiones también han sido observadas, como en el caso de Popayán por Rodríguez ${ }^{69}$, Panamá por Pinto $^{70}$, y Antioquia por Campuzano ${ }^{71}$, quien realizó el trabajo más completo en términos regionales sobre el fisco durante el siglo XVIII, abarcando la administración, el análisis de series cuantitativas y el impacto social de los estancos en el noroccidente colombiano.

Además de los trabajos regionales, se cuenta con análisis de carácter sectorial que han estudiado el impacto de las reformas, en especial el de los monopolios sobre la dinámica de apropiación de la tierra y la estructura

64 Álvaro Jara, "El financiamiento de la defensa en Cartagena de Indias: los excedentes de las cajas de Bogotá y de Quito, 1761-1802”, Historia Vol. 28 (1994).

65 Adolfo Meisel, "¿¿ituado o contrabando? La base económica de Cartagena de indias a fines del siglo de las luces”, en ¿Por qué perdió la costa Caribe el siglo XX? Y otros ensayos, ed. Adolfo Mesiel (Cartagena: Banco de la República, 2011).

66 Decsi Arévalo Hernández y Óscar Rodríguez Salazar, "La fiscalidad bajo un régimen de dominación colonial: el caso de la Caja Real de Cartagena, 1738- 1802", Anuario Colombiano de Historia Social y de la Cultura No. 35 (2008).

67 José Joaquín Pinto, “Fiscalidad e independencia en Santafé y Bogotá, 1780-1830”, América Latina en la Historia Económica Vol. 22 No. 3 (2015).

68 Edwin Muñoz, "La estructura del ingreso y del gasto en la Caja Real de Santafé, 1803-1815", Anuario Colombiano de Historia Social y de la Cultura Vol. 37 No. 2 (2011).

69 Óscar Rodríguez Salazar, “La Caja Real de Popayán, 1783-1800”, Anuario Colombiano de Historia Social y de la Cultura No. 15 (1987).

70 José Joaquín Pinto, “Fiscalidad e independencia en Panamá, 1780-1845”, Revista Tiempo \& Economía Vol. 1 No.1 (2014).

71 Rodrigo Campuzano, "Real Hacienda y reformismo borbónico en Antioquia en la segunda mitad del siglo XVIII" (tesis de Maestría en Historia, Universidad Nacional de Colombia, 1993). 
social, destacándose los trabajos de Harrison $^{72}$, Bejarano ${ }^{73}$ y González G $^{74}$. El aguardiente fue objeto de estudio de Mora $^{75}$, cuyas investigaciones permitieron conocer los pormenores de implementación del estanco, los conflictos sociales generados por la nueva política, la estructura administrativa, los rendimientos asociados a su consumo y la dinámica de producción y circulación de las mieles de caña.

Varios trabajos han intentado agrupar el factor sectorial, regional y administrativo; tal es el caso de Jara $^{76}$ quien enfatiza en la dinámica de recaudo para comprender la consolidación del sistema de defensa; Meisel ${ }^{77}$ cuya finalidad es medir el crecimiento económico a través de las series fiscales, o Rodríguez y Arévalo ${ }^{78}$ quienes se concentraron en el papel de los agentes en la configuración del sistema fiscal desde el siglo XVIII hasta finales del $\mathrm{XX}$. Otros trabajos se han preocupado por el ámbito netamente fiscal, sin embargo, su periodización abarca hasta la formación de la República, tal es el de Meisel, Jaramillo y Urrutia ${ }^{79}$ quienes intentaron dar cuenta de las trasformaciones en el sistema fiscal y monetario con una base documental reducida; Arévalo ${ }^{80}$ quien ponderó el impacto de las guerras imperiales y de independencia en la estructura de cargo y data, y últimamente Pinto ${ }^{81}$ quien estudia la dinámica y composición del cargo y data como consecuencia del desempeño económico y la política imperial desde 1780.

72 John Harrison, "The colombian tobacco industry from government monopoly to free trade, 17781870" (tesis de Doctorado en Historia, Universidad de California, 1951).

73 Jesús Antonio Bejarano y Orlando Pulido, El tabaco en una economía regional: Ambalema siglos XVIII y XIX (Bogotá: Centro de Investigaciones para el Desarrollo, Universidad Nacional de Colombia, 1985).

74 Margarita Gonzáles, "El estanco colonial del tabaco", en Ensayos de historia colonial colombiana, ed. Margarita González (Bogotá: El Áncora Editores, 1997).

75 Gilma Mora de Tovar, Aguardiente y conflictos sociales en la Nueva Granada durante el siglo XVIII (Bogotá: Universidad Nacional de Colombia, 1988).

76 Álvaro Jara, El imperio español...

77 Adolfo Meisel, Crecimiento, mestizaje...

78 Decsi Arévalo Hernández y Óscar Rodríguez Salazar, Gremios, reformas...

79 Jaime Jaramillo, Adolfo Meisel y Miguel Urrutia, "Continuities and Discontinuities in the Fiscal and Monetary Institutions of New Granada 1783-1850”, Borradores Semanales de Economía No. 74 (1997).

7080 Decsi Arévalo Hernández, "Guerra y fiscalidad en el tránsito del Virreinato a la República: Nueva Granada, 1796-1821”, Jahrbuch für Geschichte Lateinamerikas No. 48 (2011).

81 José Joaquín Pinto, "Entre colonia y república. Fiscalidad en Ecuador, Colombia y Venezuela, 17801845” (tesis de Doctorado en Historia, Universidad Nacional de Colombia, 2015). 
Desde la historia económica y fiscal se han comprendido las reformas como una serie de medidas tendientes a mejorar los resultados en algunas actividades económicas que posibilitaran un aumento del recaudo, destinado para solventar los gastos de defensa y las remisiones con destino a la metrópoli. Así las cosas, el aspecto militar y el deseo de crecimiento de la economía española fueron el motor que impulsó a los ministros del rey para llevar a cabo las reformas, mismas que se presentan como un proceso continuo y ascendente que llegaría a su cenit con los trabajos emprendidos tras la visita de Gutiérrez de Piñeres en 1778. Aunque la mayoría de los textos reconocen que las reformas se implementaron antes de 1760, gran parte de los mismos hacen referencia a los acontecimientos vividos de allí en adelante, debido al fuerte impacto que tuvo la revuelta de los comuneros y a la ausencia de series cuantitativas anteriores al reinado de Carlos III. Por último, es necesario recalcar que prevalece un esquema de interpretación en el cual la reforma se estudia de arriba abajo, donde la metrópoli formula las medidas y las mismas producen reacciones a nivel local, que en algunos casos hacen recular el impulso reformista que a la postre termina imperando.

\section{Conclusiones}

El recorrido permitió observar que la historiografía colombiana ha empleado la categoría "reformas borbónicas" haciendo referencia a las medidas implementadas por la Corona para el mejoramiento de los rendimientos de las actividades productivas, la administración y el recaudo; teniendo como finalidad el fortalecimiento del sistema de defensa, manifestándose un marcado interés por aquellas desarrolladas después 1763 tras la finalización de la Guerra de los Siete años como factor desencadenante de las políticas implantadas, cuya fuente de inspiración sería el despotismo ilustrado. En tal sentido, las reformas prefiguran un esquema de interpretación en el cual los actores locales son pasivos a la hora de implementar o diseñar alternativas a las nuevas disposiciones de la corona. Igualmente, se constató que aunque en los últimos años la lectura de las reformas como sujetas a la voluntad de los virreyes ha sido abandonada encuadrándola en el espacio atlántico, persiste el tratamiento de la temática bajo la premisa territorial de los Estados Nacionales sin incluir el papel de Panamá y Quito. 
Sin embargo, recientes investigaciones ponen en entredicho estas características, constatando la necesidad de ampliar los estudios para la primera mitad del siglo XVIII, de los motores que implicaron su desarrollo, de la periodización implícita a su estudio, de la necesaria ampliación del marco de referencia territorial no solo circunscrito a la actual Colombia y de las alternativas que diseñó el pensamiento criollo respecto a la economía colonial.

Como se vio en las anteriores secciones, existe el pleno reconocimiento que la Corona implementó una serie de medidas encaminadas al incremento de la productividad de algunos sectores tales como la agricultura, el comercio, la minería y la producción de bienes con un alto nivel de consumo como lo fueron el tabaco y el aguardiente. Sin embargo, el énfasis de los estudios se ha concentrado en los pormenores de dichas medidas a partir del reinado de Carlos III, descuidando las características de su aplicación antes de 1759, exceptuando los trabajos de Jara ${ }^{82}$, aquellos que indagaron sobre la Caja Real de Popayán ${ }^{83}$, sobre la de Cartagena ${ }^{84}$, los que estudiaron las disposiciones legales sobre el manejo de la Real Hacienda ${ }^{85}$, y los esfuerzos por entender el nivel sectorial de la producción de tabaco ${ }^{86}$, y del aguardiente ${ }^{87}$. Es decir, que para antes de 1759 solo se cuenta con un trabajo de orden general para el contexto de la Nueva Granada en el marco de la defensa del sur del Caribe, dos trabajos regionales y aportes sectoriales en torno al aspecto jurídico, la producción de tabaco y aguardiente.

Se hace preciso entonces, la ampliación de estudios que incluyan los primeros esfuerzos de formación del Virreinato, su fallida implementación, su definitiva configuración y su impacto en la Real Hacienda neogranadina. Uno de los causantes de este fenómeno es la ausencia de series cuantitativas de cargo y data para todo el periodo, salvo las reconstruidas de manera agregada por macrorregiones y quinquenios desde 1760 por Mei-

82 Álvaro Jara, El imperio español...

83 Óscar Rodríguez Salazar, La Caja Real...

84 Decsi Arévalo Hernández y Óscar Rodríguez Salazar, La fiscalidad...

85 Clímaco Calderón, Elementos...

86 Margarita Gonzáles, El estanco colonial...

87 Gilma Mora de Tovar, Aguardiente y conflictos... 
sel $^{88}$ y las agrupadas por Pinto $^{89}$ desde 1780 , mismas que no incluyen la totalidad de las Cajas.

Por otra parte, la mayoría de los trabajos establece como motor para la implementación de las reformas la necesidad de mejorar los rendimientos de la economía metropolitana con base en la instauración del monopolio comercial y de producción en América, lo cual solo se podía sostener si se contaba con un sólido sistema de defensa capaz de hacer frente a las guerras entre potencias, propiciando la aparición de nuevos ramos de recaudo y Cajas Reales. Pero no siempre las medidas fueron impulsadas por la voluntad de la Corona, algunas de ellas fueron posibles gracias al reconocimiento de situaciones de hecho que ya se manifestaban al interior del Virreinato; tal es el caso de la formación del Consulado de Cartagena ante la preponderancia de la comunidad mercantil de la ciudad en el manejo del tráfico trasatlántico ${ }^{90}$. Igual sucedió con la instauración del estanco de aguardiente debido al incremento de sus rendimientos ${ }^{91}$ y el del tabaco donde agentes particulares cumplieron un papel central para su implementación ${ }^{92}$, situación que se repite a la hora de explicar el aumento de los ingresos por alcabalas en la ciudad de Santafé, fenómeno que es asociado al trabajo del administrador Juan Díaz Herrera quien gozó de un $2 \%$ de premio por su recaudo ${ }^{93}$.

El sector minero también ofrece ejemplos del papel central que desempeñaron los actores locales para el diseño e implementación de las reformas, pues los aumentos de la producción minera en Antioquia no fueron producto de las gestiones de Mon y Velarde, José D. Elhuyar o José Celestino Mutis, quienes fungieron como reformadores expertos, debido a que la mayor parte de sus planes como el reglamento minero no fueron aplicados y la producción tuvo un auge antes de su llegada, obedeciendo más a la

88 Adolfo Meisel, Crecimiento, mestizaje...

89 José Joaquín Pinto, Entre colonia y...

90 Anthony McFarlane, "Comerciantes y monopolio en la Nueva Granada: el Consulado de Cartagena de Indias", Anuario Colombiano de Historia Social y de la Cultura No. 11 (1983).

91 Gilma Mora de Tovar, Aguardiente y conflictos...

92 Renée Soulodre-La France, Región e imperio...

93 Margarita Restrepo, Nueva Granada en tiempo... 
dinámica de los precios afectada por la parálisis del comercio externo en épocas de guerras, los premios pagados por la Real Hacienda por el cambio de doblones o el mercado crediticio, como lo ha demostrado Torres ${ }^{94}$. Igualmente, la creación de la Casa de la Moneda de Popayán se debió más a la iniciativa privada que al querer de la Corona, ya que desde 1725 el gobernador y cabildo de la provincia habían elevado la petición al Consejo de Indias ${ }^{95}$.

Otro de los aspectos problemáticos frente al modo de tratamiento de la categoría hace referencia a la comprensión de las medidas como un proceso ascendente que posibilitó el incremento del recaudo con base en un desarrollo armónico de los procedimientos técnicos e instancias institucionales de recaudo. Ello no es totalmente cierto si se toman en cuenta al menos tres factores: la oposición a las medidas, las guerras entre potencias y el comportamiento de las actividades productivas. De hecho, lo que se constata en la historia lineal compuesta alrededor de los pormenores de los gobiernos de cada virrey, es un proceso marcado por diversos avances y retrocesos que obedecen a la respuesta interna a las nuevas medidas aplicadas o al impacto que tuvieron, conjugadas con el escenario de la guerra entre potencias, como lo muestra Ortiz ${ }^{96}$. De esta manera se hacen evidentes al menos cinco periodos:

- 1717-1739: Marcado por la instauración del primer virreinato y su temprana supresión debido a la reacción de distintos sectores, entre los que se destaca la oposición de los oidores de la Real Audiencia, escasamente estudiado por la historia fiscal y cuyos principales análisis son aportados por Groot ${ }^{97}$, y desde la historia institucional con las obras de Ortiz $^{98}$ y Garrido 99 .

- 1739-1760: En el primer año se instaura definitivamente el virreinato como estrategia de defensa en medio de la Guerra de la Oreja de Jenkins, durante el cual se crearon los primeros estancos y la casa de

94 James Torres, Minería y moneda en el nuevo...

95 Margarita Restrepo, Nueva Granada en tiempo...

96 Sergio Elías Ortiz, Gobernantes de capa...

97 José Manuel Groot, Historia eclesiástica...

98 Sergio Elías Ortiz, Gobernantes de capa...

99 María Teresa Garrido Conde, La primera creación... 
moneda de Santafé se erigió bajo la administración directa, mientras la de Popayán inició su funcionamiento. Para este periodo encontramos importantes trabajos desde el punto de vista del fisco regional de Popayán $^{100}$ y de Cartagena ${ }^{101}$.

- 1760-1778: El primer reformismo carolino es fundamental toda vez que allí se dieron importantes trasformaciones en el escenario fiscal de la mano del gobierno del virrey Solís, como lo demostró Restrepo ${ }^{102}$. Indudablemente el trabajo más completo al respecto es el desarrollado por Pogonyi ${ }^{103}$ mismo que no ha sido publicado y que sirvió de base para el trabajo de Meisel ${ }^{104}$; a pesar de ello las series cuantitativas que emplean no están segregadas mostrando los sumarios de cargo y data por Cajas Reales y las tensiones sociales que se experimentaron.

- 1778-1795: Este periodo está marcado por la visita de Gutiérrez de Piñeres como regente visitador, cuyas principales medidas fueron aplazadas debido a la guerra que se libraba contra Inglaterra y los desórdenes internos provocados por la revuelta de los comuneros, fenómenos que han sido ampliamente estudiados. Sin embargo, las reformas poco tiempo después fueron desarrolladas por Caballero y Góngora quien posibilitó el comercio con neutrales y colonias extranjeras incrementando los rendimientos de algunas actividades productivas, además de ello abandonó el cargo con la formulación del plan de intendencias para la Nueva Granada.

- 1795-1808: Este periodo ha sido poco estudiado, marcado por la imposibilidad de implementación del sistema de intendencias y la prohibición del comercio con neutrales y colonias extranjeras. Recientes investigaciones han mostrado cómo el cierre del comercio afectó la producción minera ${ }^{105}$ y cómo ello deterioró el recaudo en las Cajas Reales propiciando una suerte de freno al impulso reformista ${ }^{106}$, causa-

100 Óscar Rodríguez Salazar, La Caja Real...

101 Decsi Arévalo Hernández y Óscar Rodríguez Salazar, La fiscalidad...

102 Margarita Restrepo, Nueva Granada en tiempo...

103 Micklos Pogonyi, The search...

104 Adolfo Meisel, Crecimiento, mestizaje...

105 James Torres, Minería y moneda...

106 José Joaquín Pinto, Entre colonia y... 
do por la muerte de Gálvez y la implementación de un nuevo modelo reformador ${ }^{107}$ o por la revuelta comunera ${ }^{108}$.

La determinación de dicha periodización reporta que las reformas no fueron un proceso armónico de constante avance, sino un fenómeno atravesado por coyunturas locales y externas que posibilitaron o frenaron su desarrollo. Por último, es preciso reseñar que la mayor parte de los trabajos, a excepción de los de Jara ${ }^{109}$ y Pinto ${ }^{110}$, se circunscriben al estudio del fisco en el marco territorial de la actual Colombia, dejando de lado que esta incluía a Panamá fuertemente vinculada a Cartagena, Santafé enviaba situados a Maracaibo o que Guayaquil remitió fondos por intermedio de Quito cuyo destino final era Cartagena, hechos que implican una ampliación de los marcos de referencia para entender la dinámica fiscal del Virreinato, prescindiendo de las construcciones territoriales propias del periodo republicano.

Estas observaciones dejan claro que para futuros trabajos en torno a la fiscalidad en el Virreinato de la Nueva Granada durante el siglo XVIII se hace preciso ampliar la periodización iniciando por lo menos desde 1717, sin centrarse de manera puntual en 1778 con la visita de Gutiérrez de Piñeres, pues previo a ella ya existían procesos de trasformación. Igualmente, es importante resaltar el papel que agentes locales tuvieron para la implementación de las medidas y no solo comprenderlas como dictámenes desde la metrópoli, dentro de un esquema que comprenda el proceso reformista no como un fenómeno continuo de avance sino como sujeto a sobresaltos, lo que permite establecer una periodización. Por último, es fundamental que la temática sea tratada desde un espacio más amplio que el de la República de Colombia, pues el Virreinato abarcaba más territorios - no solo en términos formales- ya que las regiones entablaban intercambios entre cada una de ellas, lo cual implica multiplicar esfuerzos para la elaboración de series cuantitativas que reporten la dinámica de cargo y data en cada una de las Cajas Reales.

107 Luis Navarro García, "La crisis del reformismo borbónico bajo Carlos IV", Temas Americanistas No. 13 (1997).

108 John Leddy Phelan, El pueblo...

109 Álvaro Jara, El imperio español...

110 José Joaquín Pinto, Entre colonia y... 


\section{Bibliografía}

\section{Libros}

Alameda, Raúl. Virreyes y funcionarios neogranadinos ante las reformas borbónicas, 1729-1818. Bogotá: Academia Colombiana de Ciencias Económicas, 2014.

Alzate, Adriana. Suciedad y orden: Reformas sanitarias borbónicas en la Nueva Granada 1760-1810. Universidad del Rosario, 2007.

Arévalo, Decsi, y Óscar Rodríguez Salazar. Gremios, reformas tributarias y administración de impuestos en Colombia. Bogotá: Universidad Externado, 2001.

Bejarano, Jesús Antonio, y Orlando Pulido. El tabaco en una economía regional: Ambalema siglos XVIII y XIX. Bogotá: Centro de Investigaciones para el Desarrollo Universidad Nacional de Colombia, 1985.

Bohórquez, Jesús. Luces para la economía. Libros y discursos de economía política en el Atlántico español durante la era de las revoluciones (Nueva Granada, 1780-1811). Bogotá: Instituto Colombiano de Antropología e Historia, 2013.

Calderón, Clímaco. Elementos de hacienda pública. Bogotá: La Luz, 1911. Colmenares, Germán. Historia económica y social de Colombia. Bogotá: Tercer Mundo, 1997.

Colmenares, Germán. Relaciones de mando e informes de los gobernantes de la Nueva Granada. Bogotá: Banco Popular, 1989.

Cruz Santos, Abel. Economía y Hacienda Pública. Bogotá: Lerner, 1965.

Díaz, Zamira. Guerra y economía en las haciendas. Popayán, 1780-1830. Cali: Universidad del Valle, 1983.

Fisher, John, Allan Kuethe y Anhotny McFarlane. Reform and Insurrection in Bourbon New Granada and Peru. Louisiana: Louisiana State University Press, 1990.

Garrido Conde, María Teresa. La primera creación del virreinato de Nueva Granada, 1717-1723. Sevilla: Escuela de Estudios Hispanoamericanos, 1965.

Groot, José Manuel. Historia eclesiástica y civil de Nueva Granada. Bogotá: Medardo Rivas, 1869.

Herrera Ángel, Martha. Poder local, población y ordenamiento territorial en la Nueva Granada, siglo XVIII. Bogotá: Archivo General de la Nación, 1996. 
Herrera Ángel, Martha. Ordenar para controlar: Ordenamiento espacial y control político en las Llanuras del Caribe y en los Andes centrales neogranadinos, siglo XVIII. Bogotá: Universidad de los Andes, 2014.

Jara, Álvaro. El imperio español en América (1700-1820). Santiago de Chile: Editorial Sudamericana, 2011.

Kuethe, Allan. Reforma militar y sociedad en la Nueva Granada: 17731808. Bogotá: Banco de la República, 1993.

Liévano Aguirre, Indalecio. Los grandes conflictos sociales y económicos de nuestra historia. Bogotá: Ediciones Tercer Mundo, 1964.

Maqueda, Consuelo. El Virreinato de la Nueva Granada, 1717-1780. Estudio institucional. Madrid: Dykinson/Ediciones Puertollano, 2007.

Marchena, Juan. Ejército y milicias en el mundo colonial americano. Madrid: Mapfre, 1992.

McFarlane, Anthony. Colombia antes de la independencia. Economía, sociedad y política bajo el dominio Borbón. Bogotá: Banco de la República, 1997.

Mora de Tovar, Gilma. Aguardiente y conflictos sociales en la Nueva Granada durante el siglo XVIII. Bogotá: Universidad Nacional de Colombia, 1988.

Nieto Arteta, Luis Eduardo. Economía y cultura en la historia de Colombia. Bogotá: Ediciones Tercer Mundo, 1962.

Ortiz, Sergio Elías. Gobernantes de capa y espada, Tomos I y II. Bogotá: Ediciones Lerner, 1970.

Ots Capdequi, José María. Instituciones de Gobierno del Nuevo Reino de Granada durante el siglo XVIII. Bogotá: Universidad Nacional de Colombia, 1951.

Patiño, Beatriz. Riqueza, pobreza y diferenciación social en la Provincia de Antioquia durante el siglo XVIII. Medellín: Universidad de Antioquia, 2011.

Phelan, John Leddy. El pueblo y el Rey. Bogotá: Carlos Valencia Ediciones, 1978.

Posada, Eduardo, y Pedro Ibáñez. Relaciones de mando. Memorias presentadas por los gobernantes del Nuevo Reino de Granada. Bogotá: Imprenta Nacional, 1910.

Restrepo, José Manuel. Historia de la revolución de la República de Colombia. París: Librería Americana, 1827. 
Restrepo, Margarita. Nueva Granada en tiempo del virrey Solís, 17531761. Bogotá: Universidad del Rosario, 2009.

Samper, José María. Ensayo sobre las revoluciones políticas y la condición social de las repúblicas colombianas. París: Imprenta de E. Thunot y Cía., 1861.

Serrano, José Manuel. Fortificaciones y tropas: el gasto militar en tierra firme, 1700-1788. Sevilla: Escuela de Estudios Hispanoamericanos, 2004.

Silva, Renán. Cultura escrita, historiografía y sociedad en el Virreinato de la Nueva Granada. Bogotá: La Carreta Editores, 2015.

Soulodre-La France, Renée. Región e imperio: el Tolima Grande y las reformas borbónicas en el siglo XVIII. Bogotá: Instituto Colombiano de Antropología e Historia, 2004.

Torres, James. Minería y moneda en el Nuevo Reino de Granada. El desempeño económico en la segunda mitad del siglo XVIII. Bogotá: Instituto Colombiano de Antropología e Historia, 2013.

Twinam, Ann. Mineros, comerciantes y labradores: las raíces del espíritu empresarial en Antioquia, 1763-1810. Medellín: Fondo Rotatorio de Publicaciones FAES, 1985.

\section{Artículos de libro}

Galindo, Aníbal. "Apuntamientos para la historia económica y fiscal del país”. En Estudios económicos y fiscales, editado por Aníbal Galindo. Bogotá: Imprenta de H. Andrade, 1880, 169-256.

González, Margarita. "El estanco colonial del tabaco”. En Ensayos de historia colonial colombiana, editado por Margarita González. Bogotá: El Áncora Editores, 1997, 71-182.

Meisel, Adolfo. "¿Situado o contrabando? La base económica de Cartagena de Indias a fines del Siglo de las Luces”. En ¿Por qué perdió la costa Caribe el siglo XX? Y otros ensayos, editado por Adolfo Mesiel. Cartagena: Banco de la República, 2011, 9-58.

\section{Artículos en revista}

Arévalo Hernández, Decsi, y Óscar Rodríguez Salazar. "La fiscalidad bajo un régimen de dominación colonial: el caso de la Caja Real de Cartagena, 1738-1802". Anuario Colombiano de Historia Social y de la Cultura No. 35 (2008): 19-63. 
Arévalo, Decsi. “Guerra y fiscalidad en el tránsito del Virreinato a la República: Nueva Granada, 1796-1821”. Jahrbuch für Geschichte Lateinamerikas No. 48 (2011): 31-56.

Bohórquez, Jesús. "Más para entretener la miseria que despertar la codicia: los frutos del comercio y los mercados imperiales durante el nacimiento del liberalismo. Nueva Granada, 1780-1810”. Anuario Colombiano de Historia Social y de la Cultura Vol. 36 No. 1 (2009): 17-63.

Conde Calderón, Jorge. "Reformas borbónicas y reordenamiento del espacio en el Nuevo Reino de Granada. El caso de la Providencia de Cartagena siglo XVIII". Revista Historia Caribe No. 1 (1995): 5-24.

Gonzáles, Margarita. "El resguardo minero de Antioquia". Anuario Colombiano de Historia Social y de la Cultura No. 9 (1979): 17-37.

González, Margarita. "La política económica virreinal en el Nuevo Reino de Granada: 1750-1810”. Anuario Colombiano de Historia Social y de la Cultura No. 11 (1983): 129-186.

Jara, Álvaro. "El financiamiento de la defensa en Cartagena de Indias: los excedentes de las Cajas de Bogotá y de Quito, 1761-1802”. Historia Vol. 28 (1994): 117-182.

Jaramillo, Jaime, Adolfo Meisel y Miguel Urrutia. "Continuities and Discontinuities in the Fiscal and Monetary Institutions of New Granada 1783-1850”. Borradores Semanales de Economía No. 74 (1997): $1-51$.

Kalmanovitz, Salomón. 'El PIB de la Nueva Granada en 1800: auge colonial, estancamiento republicano". Revista de Economía Institucional Vol. 8 No. 15 (2006): 161-183.

McFarlane, Anthony. "El comercio exterior del Virreinato de la Nueva Granada: Conflictos en la política económica de los Borbones, 1783-1789'. Anuario Colombiano de Historia Social y de la Cultura No. 6-7 (1972): 43-69.

McFarlane, Anthony. "Comerciantes y monopolio en la Nueva Granada: el Consulado de Cartagena de Indias". Anuario Colombiano de Historia Social y de la Cultura No. 11 (1983): 43-70.

Meisel, Adolfo. "Crecimiento, mestizaje y presión fiscal en el Virreinato de la Nueva Granada, 1760-1800". Cuadernos de Historia Económica y Empresarial No. 28 (2011): 1-96. 
Mora, Gilma. "Las cuentas de la Real Hacienda y la política fiscal en el Nuevo Reino de Granada: Materiales para su estudio a fines del siglo XVIII". Anuario Colombiano de Historia Social y de la Cultura No. 11 (1983): 305-335.

Moreno, Nathalie. "Circulación de efectos de Castilla en el Virreinato de la Nueva Granada a finales del siglo XVIII”. Fronteras de la Historia Vol. 18 No. 1 (2013): 211-249.

Muñoz, Edwin. "La estructura del ingreso y del gasto en la Caja Real de Santafé, 1803-1815”. Anuario Colombiano de Historia Social y de la Cultura Vol. 37 No. 2 (2011): 45-85.

Muñoz, Edwin, y James Torres. "La función de Santafé en los sistemas de intercambio en la Nueva Granada a fines del siglo XVIII". Fronteras de la Historia Vol. 18 No. 1 (2013): 165-210.

Navarro García, Luis. "La crisis del reformismo borbónico bajo Carlos IV”. Temas Americanistas No. 13 (1997): 1-22.

Pinto, José. "Fiscalidad e independencia en Panamá, 1780-1845”. Revista Tiempo \& Economía Vol. 1 No. 1 (2014): 11-37.

Pinto, José. "Fiscalidad e independencia en Santafé y Bogotá, 1780-1830". América Latina en la Historia Económica Vol. 22 No. 3 (2015): 7-43. Rodríguez Salazar, Óscar. "Anotaciones al funcionamiento de la Real Hacienda en el Nuevo Reino de Granada siglo XVIII". Anuario Colombiano de Historia Social y de la Cultura No. 11 (1983): 71-88.

Rodríguez Salazar, Óscar. “La Caja Real de Popayán, 1783-1800”. Anuario Colombiano de Historia Social y de la Cultura No. 15 (1987): 5-36.

Rodríguez Salazar, Óscar. "El pensamiento económico en la formación del Estado granadino, 1780-1830”. Historia Crítica No. 3 (1990): 93110.

Ruiz Rivera, Julián. "El reformismo local en el Virreinato de la Nueva Granada". Temas Americanistas No. 13 (1997): 80-98.

Torres, James. "El comportamiento de losprecios en una economía preindustrial: Popayán, Virreinato de Nueva Granada, 1706-1819”. Cuadernos de Economía Vol. 34 No. 66 (2015): 629-680.

Torres, James. "Monedas de antiguo y nuevo cuño. Envilecimiento y reacuñación en el Nuevo Reino de Granada en la segunda mitad del siglo XVIII". Memoria y Sociedad Vol. 18 No. 36 (2014): 121-136. 
Torres, James. "Tasas de interés y desempeño económico: el crédito comercial en Santafé de Bogotá, 1760-1810”. América Latina en la Historia Económica Vol. 21 No. 3 (2014): 9-45.

\section{Tesis}

Brungardt, Maurice. "Tithe production and patterns of economic change in central Colombia, 1764-1833". (Tesis de Doctorado en Historia, University of Texas, Austin, 1974).

Campuzano, Rodrigo. "Real Hacienda y reformismo borbónico en Antioquia en la segunda mitad del siglo XVIII". (Tesis de Maestría en Historia, Universidad Nacional de Colombia, 1993).

Harrison, John. "The colombian tobacco industry from government monopoly to free trade, 1778-1870”. (Tesis de Doctorado en Historia, Universidad de California, 1951).

Pinto, José. "Entre colonia y república. Fiscalidad en Ecuador, Colombia y Venezuela, 1780-1845”. (Tesis de Doctorado en Historia, Universidad Nacional de Colombia, 2015).

Pogonyi, Micklos. "The search for trade and profits in Bourbon Colombia: 1765-1777'. (Tesis de Doctorado en Historia, The University of New Mexico, 1978).

\section{Publicaciones en Internet}

Melo, Jorge Orlando. La producción agrícola en Popayán en el siglo XVIII, según las cuentas de diezmos, 1979. http://jorgeorlandomelo.com/bajar/popayan.pdf (11/07/2015).

Melo, Jorge Orlando. Producción de oro y desarrollo económico en el siglo XVIII, 1997. http://www.jorgeorlandomelo.com/bajar/oroydesarrollo.pdf

Para citar este artículo: Pinto Bernal, José Joaquín. "El reformismo fis-

82 cal borbónico en la Nueva Granada, balance y perspectivas”, Historia Caribe Vol. XI No. 29 (Julio-Diciembre 2016): 53-82. DOI: http://dx.doi. org/10.15648/hc.29.2016.4 